\title{
Land subsidence and associated ground fracturing: study cases in central Mexico with ALOS-2 PALSAR-2 ScanSAR Interferometry
}

\author{
Tazio Strozzi ${ }^{1}$, Dora Carreon-Freyre ${ }^{2}$, and Urs Wegmüller ${ }^{1}$ \\ ${ }^{1}$ Gamma Remote Sensing, Gümligen, Switzerland \\ ${ }^{2}$ Centro de Geociencias, Universidad Nacional Autónoma de México, Queretaro, Mexico \\ Correspondence: Tazio Strozzi (strozzi@gamma-rs.ch)
}

Published: 22 April 2020

\begin{abstract}
Land subsidence affects highly developed urban areas in central Mexico, where inhabitants rely on groundwater for about $60 \%$ of water supply and most of the cities are located in volcanic valleys filled with fine and coarse grained sediments. Compaction associated to groundwater depletion in areas with subsoil contacts sediments-rock have caused differential subsidence, ground fracturing and eventually the reactivation of preexisting faults, depending on the local geological setting. Remote sensing monitoring methods of land deformation have proved to be useful tools to assess this geological hazard for urban planning. We used L-band ScanSAR data from the ALOS-2 PALSAR-2 mission to produce a regional land subsidence map over an area of about $350 \mathrm{~km} \times 350 \mathrm{~km}$ over central Mexico. Our results indicate with a remarkable spatial coverage widespread land subsidence over the major cities, which is ranging from more than $30 \mathrm{~cm} \mathrm{yr}^{-1}$ in Mexico City to $5-10 \mathrm{~cm} \mathrm{yr}^{-1}$ in other locations.
\end{abstract}

\section{Introduction}

Land subsidence is a generalized problem in the urban areas of central Mexico (e.g. Vega, 1976; Tuxpan-Vargas et al., 2018; Carreon-Freyre et al., 2019). These cities had a rapid development in the last thirty years and rely on groundwater for more than $60 \%$ of the water supply. The use of land and subsurface resources represents a great challenge for the natural resources management and urban planning agencies. Furthermore, differential compaction of sediments and volcanic materials associated to groundwater depletion have caused earth fissures, ground fracturing and reactivation of pre-existing faults, depending on their local geological setting. In some areas, geological faulting controls the propagation of deformation. The majority of the cities affected by subsidence are located in the Trans-Mexican Volcanic Belt (TMVB), forming a strip of 20-200 km wide and nearly $1000 \mathrm{~km}$ long, where valleys are often bounded by faults and/or volcanic structures of ages ranging from the Miocene to the Quaternary (Ferrari et al., 2007; TuxpanVargas et al., 2018). The stratigraphy below the cities con- sists of fluvial and/or lacustrine sediments often interbedded with layers of pyroclastic materials and lava flows.

Central Mexico is located at a low latitude and at high altitudes, which range between 1500 and $2800 \mathrm{~m}$ above sea level. The climate is subtropical, mild or warm during the day and cool or cold during the night depending on the season. According to Copernicus Sentinel-2 data of the time period 2016-2018 processed by the ESA-CCI land cover project (https://www.esa.int/spaceinimages/Images/2018/10/ Mapping_Mexico_s_land_cover, last access: 7 November 2019), the land cover includes cropland, grassland, aquatic vegetation and built up areas in the basins, with shrubs and trees at higher elevation (Fig. 1).

\section{ALOS-2 PALSAR-2 ScanSAR Interferometry}

As already demonstrated with past missions (Strozzi et al., 2003; Chaussard et al., 2014), L-band SAR data are specially suited for geophysical applications because of the reduced temporal decorrelation and enhanced capability to map rapid displacements. The Advanced Land Observation Satellite 2 


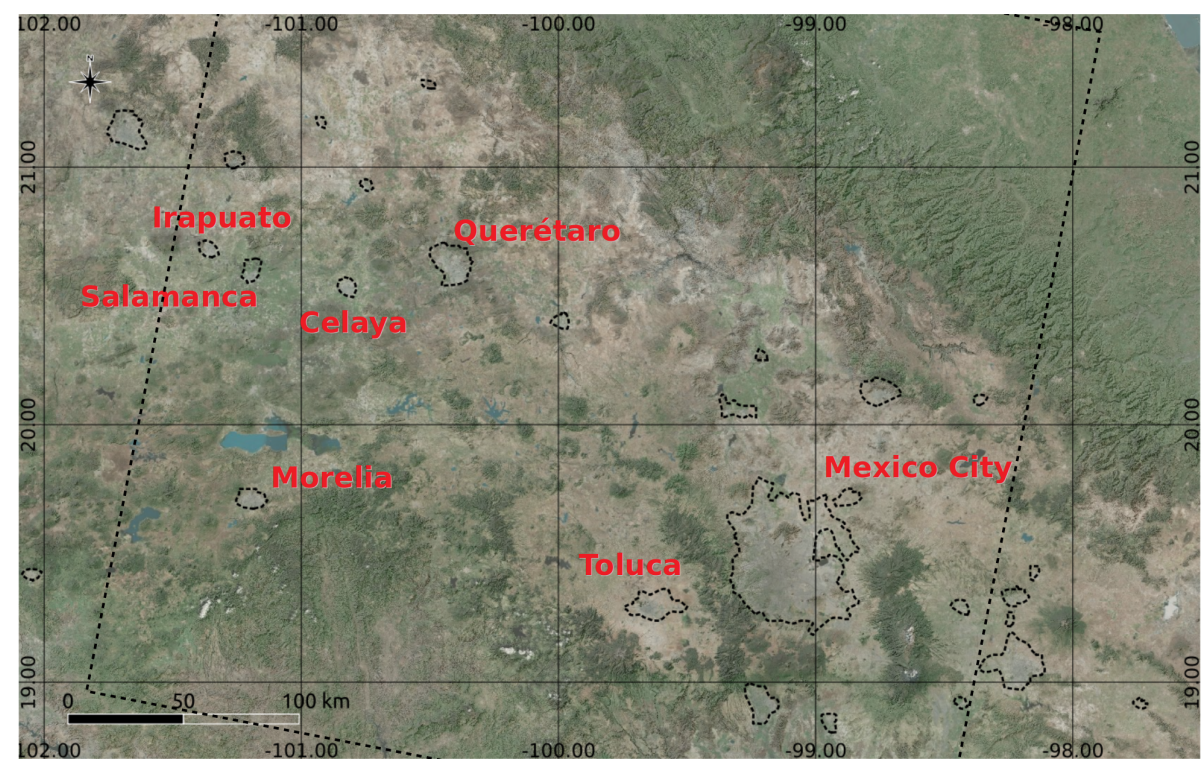

Figure 1. Bing imagery ( $($ C Microsoft) of Central Mexico overlay to a shaded relief of the SRTM digital elevation model with urban areas extents from MODIS data (Schneider et al., 2009).

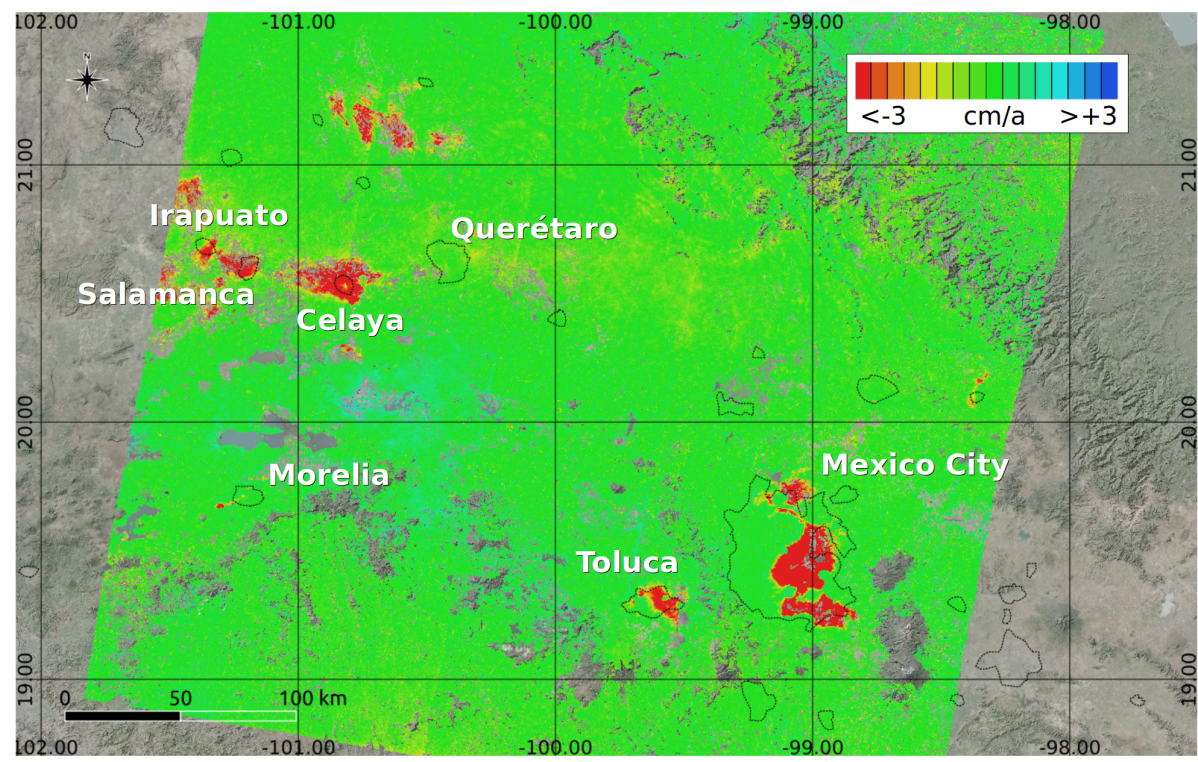

Figure 2. Land subsidence in central Mexico from ALOS-2 PALSAR-2 ScanSAR interferometry between 20 February 2015 and 16 February 2018. Colour scale is saturated at $3 \mathrm{~cm} \mathrm{yr}^{-1}$. Map data are from Bing Aerial (C Microsoft), urban areas extents from MODIS data (Schneider et al., 2009).

Phased Array L-band SAR 2 (ALOS-2 PALSAR-2) mission design represents a consolidated approach for conducting research and development activities over wide areas. The ALOS-2/PALSAR-2 Basic Observation Scenario (https:// www.eorc.jaxa.jp/ALOS-2/en/obs/pal2_obs_guide.htm, last access: 7 November 2019) encompasses for central Mexico a large number of interferometric acquisitions in ScanSAR mode since August 2014 with a repetition rate of approximately 42 days. ScanSAR data exhibit much larger swath width compared to Stripmap data (i.e., $350 \mathrm{~km}$ vs. $70 \mathrm{~km}$ ) and accordingly can cover wider areas although at a moderate nominal resolution of approximately $100 \mathrm{~m}$.

In our analyses we considered 23 burst synchronized ALOS-2 PALSAR-2 ScanSAR acquisitions from 20 February 2015 to 16 February 2018 distributed by the Japan Aerospace Exploration Agency (JAXA) in single-look complex format and dual-polarisation (HH and HV). Multitemporal interferometric analysis of the $\mathrm{HH}$ polarisation data 


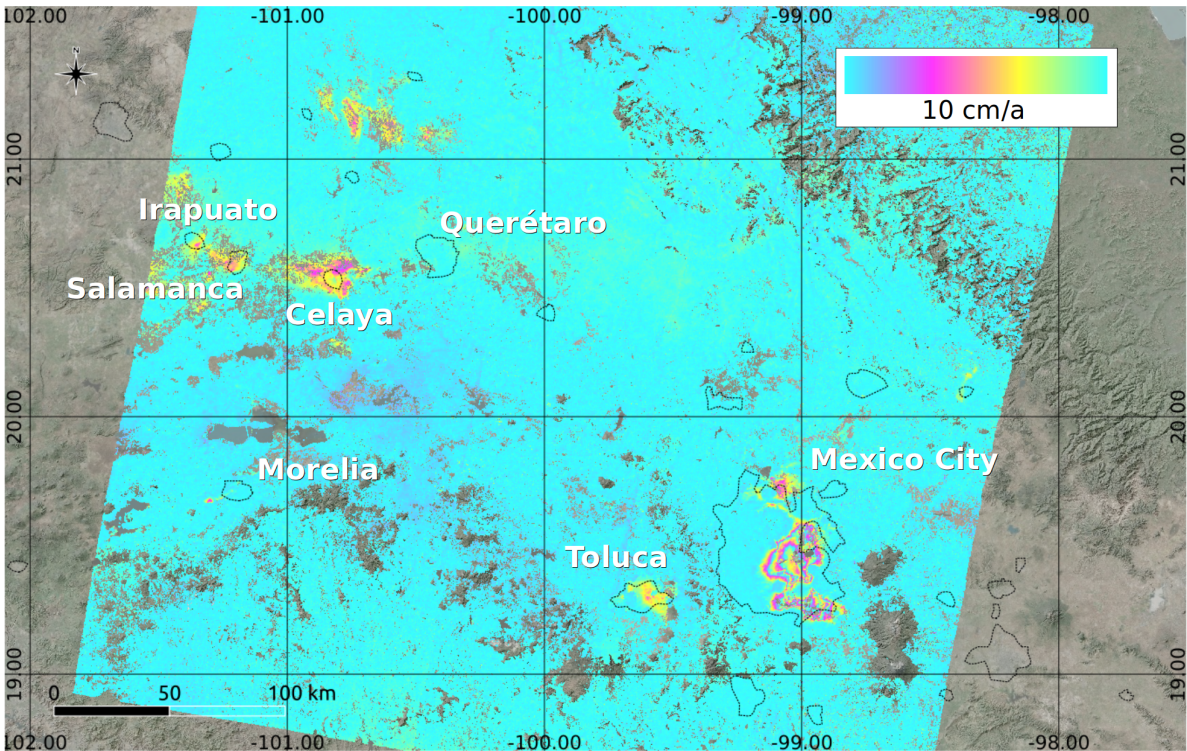

Figure 3. Land subsidence in central Mexico from ALOS-2 PALSAR-2 ScanSAR interferometry between 20 February 2015 and 16 February 2018. A cyclic colour scaling model is employed to highlight larger rates of motion in Mexico City. Map data are from Bing Aerial (C) Microsoft), urban areas extents from MODIS data (Schneider et al., 2009).
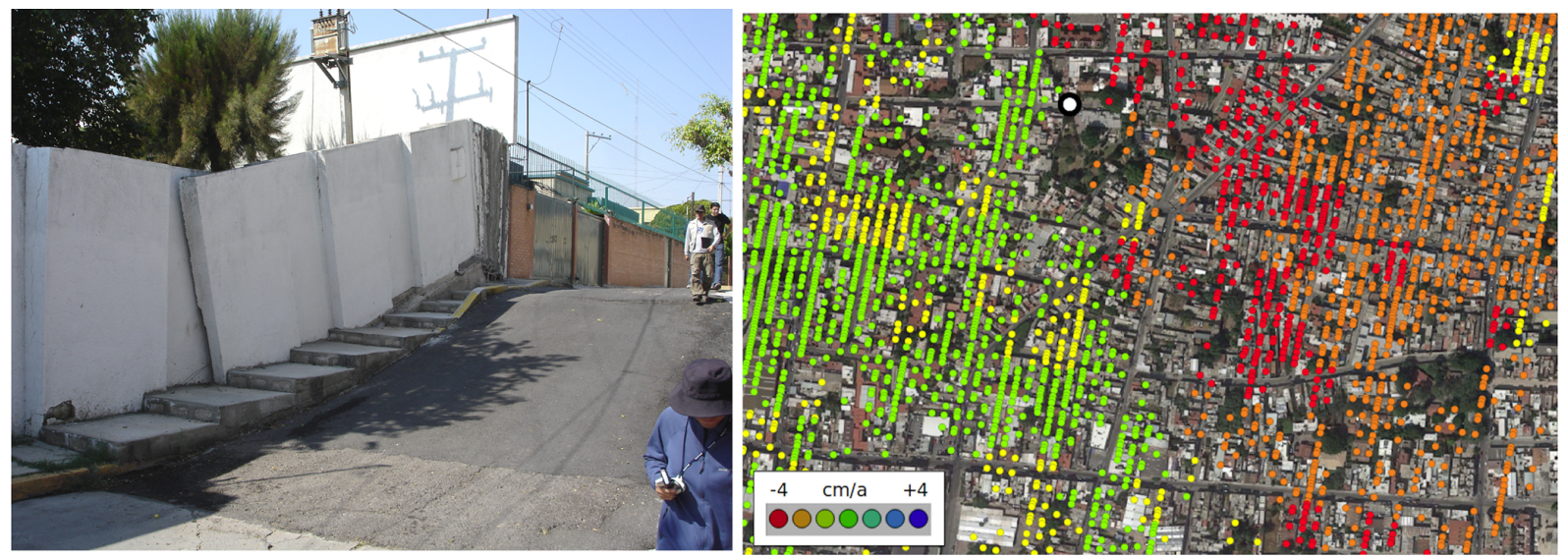

Figure 4. Celaya City (Guanajuato State): photograph of a road crossed by a geological fault (Sonora 206, Col. Centro, 38000 Celaya, Gto., Mexico) and extract of the subsidence map from ALOS-2 PALSAR-2 ScanSAR interferometry between 20 February 2015 and 16 February 2018. The dot on the subsidence map indicates the location where the photograph was taken. Map data are from Bing Aerial (@) Microsoft).

was performed combining point (i.e. persistent scatterers) and multi-looked (i.e. small baseline) phases, adopting the 8 February 2016 image as central reference with a baseline distribution of approximately $\pm 300 \mathrm{~m}$. The five bursts of the ScanSAR data were analysed independently and the resulting displacement maps mosaicked.

\section{Results}

In accordance with previous InSAR studies (e.g. Strozzi et al., 1999; Carnec et al., 2000; Cigna, et al., 2012; Chaussard et al., 2014), our results indicate widespread land subsidence over the major cities of central Mexico. Linear vertical rates are ranging from more than $30 \mathrm{~cm} \mathrm{yr}^{-1}$ in Mexico City to 5$10 \mathrm{~cm} \mathrm{yr}^{-1}$ in other locations, including many non urban areas (Fig. 2). The extension of the deformation zones in Mexico City is mainly conditioned by the topography of the basin and in the last years subsidence is propagating to the east and to the north of the basin. Differential settlements over short distances are common, see Fig. 3 where the subsidence rate is represented with a cyclic colour scaling model to highlight the gradients. The density of points with valid information is high not only over urban areas but also over grassland and shrubs and around croplands and wetlands. The coverage 
with valid information is decreasing over more densely vegetated areas at higher elevation and, as expected, over water and cultivated fields. On a local scale, as for instance over a geological fault in Celaya City (Guanajuato State) (Fig. 4), the low resolution of ALOS-2 PALSAR-2 ScanSAR data results in a grid of points less dense than mapped with other sensors.

\section{Discussion and Conclusions}

ALOS-2 PALSAR-2 ScanSAR interferometry is a robust remote sensing method for monitoring land subsidence over wide areas and assessing this geological hazard to be considered in urban planning. Despite the moderate spatial resolution, local areas subject to differential settlements can be discriminated, as shown by the alignment of deformation in the Irapuato-Celaya area and in rural areas at the northwest of Queretaro, where agriculture is the main economical activity. In order to prevent and manage the damage to urban infrastructure, more efforts need to be addressed for the implementation of in-situ monitoring techniques. In addition, a great challenge is faced for urban development and natural resources management in order to govern the decrease of surfical and groundwater water availability in urban areas for the next years. Urban planning decision making should integrate not only geotechnical but also geological risk zonations, improvement of water distribution systems and control of groundwater extraction. Detailed geological, hydrogeological, geomechanical and morphological characterization should be accompanied by remote and in-situ surveying of deformation.

Data availability. The majority of the data presented here are from an ongoing and yet incomplete project. The datasets generated during the current study are available on request from the corresponding authors.

Author contributions. TS and UW processed the satellite SAR images; DCF contributed to the discussion and validation; TS led the writing of the paper; all authors analyzed the results and contributed to the writing of the paper.

Competing interests. The authors declare that they have no conflict of interest.

Special issue statement. This article is part of the special issue "TISOLS: the Tenth International Symposium On Land Subsidence - living with subsidence". It is a result of the Tenth International Symposium on Land Subsidence, Delft, the Netherlands, 17-21 May 2021.
Acknowledgements. ALOS-2 PALSAR-2 provided by JAXA, courtesy of RA4-1058 "Displacement mapping using PALSAR-2 DINSAR, PSI and tracking”.

\section{References}

Carreon-Freyre, D., Cerca, M., Gutierrez-Calderon, R., AlcantaraDuran, C., Strozzi, T., and Teatini, P.: Land Subsidence and associated ground fracturing in urban areas, Study cases in central Mexico, Proc. of the XVI Pan-American Conference on Soil Mechanics and Geotechnical Engineering, 9 pp., 2019.

Carnec, C., Raucoules, D., Ledoux, E., Huré, A.. and Rivera, A.: Mapping and modelling of major urban subsidence on Mexico City from radar interferometry, Int. Conf. Research and Application on Hydrogeological Disarray in the World, The Fragile Territory, Rome, Italy, 7-10 December 2000.

Chaussard, E., Wdowinski, S., Cabral-Cano, E., and Amelung, F.: Land subsidence in central Mexico detected by ALOS InSAR time-series, Remote Sens. Environ, 140, 94-106, 2014.

Cigna, F., Osmanoglu, B., Cabral-Cano, E., Dixon, T., ÁvilaOlivera, J., Garduño Monroy, V., Demets, C., and Wdowinski, S.: Monitoring land subsidence and its induced geological hazard with Synthetic Aperture Radar Interferometry: A case study in Morelia, Mexico, Remote Sens. Environ, 117, 146-161, 2012.

Ferrari, L., Rosas-Elguera, J., Carrasco-Núñez, G., OrozcoEsquivel, M. T., and Norato-Cortéz, T.: Cartografía Geológica Digital de la Faja Volcánica Transmexicana y áreas adyacentes, Digital Geosciences, Vol. 2, J. Int. Geosc. Cartography, 2007.

Schneider, A., Friedl, M. A., and Potere, D.: A new map of global urban extent from MODIS data, Environ. Res. Lett., 4, 044003, https://doi.org/10.1088/1748-9326/4/4/044003, 2009.

Strozzi, T. and Wegmüller, U.: Land subsidence in Mexico City mapped by ERS differential SAR interferometry, IGARSS'99, IEEE 1999 International Geoscience and Remote Sensing Symposium, 4, 1940-1942, https://doi.org/10.1109/IGARSS.1999.774993, 1999.

Strozzi, T., Wegmuller, U., Werner, C. L., Wiesmann, A., and Spreckels, V.: JERS SAR interferometry for land subsidence monitoring, IEEE T. Geosci. Remote, 41, 1702-1708, 2003.

Tuxpan-Vargas, J., AlfredoRamos-Leal, J., Manuel HernándezMadrigal, V., and Villaseñor-Reyes, C.: Land subsidence by groundwater over-exploitation from aquifers in tectonic valleys of Central Mexico: A review, Eng. Geol., 246, 91-106, 2018.

Vega, F. G. E.: Subsidence of the city of Mexico: a historical review, Proc. 2nd Int. Symp. Land Subidence, Anaheim, International Association of Hydrological Sciences, UNESCO publication No., 121, 35-38, 1976. 